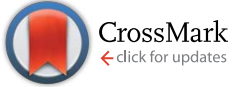

Cite this: RSC Adv., 2017, 7, 7033

\title{
Effect of the surface properties of resorcinol- formaldehyde resin/carbon nanocomposites and their carbonization products on the solid-phase extraction of explosives $\dagger$
}

\begin{abstract}
Viktor M. Bogatyrov, ${ }^{a}$ Mariia V. Galaburda, ${ }^{a}$ Waldemar Tomaszewski ${ }^{\star b}$ and Jadwiga Skubiszewska-Zięba ${ }^{c}$

Two polymer-nanocarbon composites, containing carbon nanotubes or exfoliated graphite, were prepared using resorcinol-formaldehyde resin. By carbonization of the composites, two additional carbon-based nanomaterials were obtained. The resulting materials were investigated with respect to their textural and morphological characteristics. The prepared composites were employed as sorbents for the separation of explosives (nitramines, nitrate esters and nitroaromatics) from aqueous samples by solid-phase extraction (SPE). The SPE results, i.e., the adsorption and desorption rates, are separately discussed. Both polymeric and carbonized composites (with nanotubes as a filler) gave high recovery rates, which reached $90 \%$, and proved to be very effective for the extraction of explosives. The observed differences in the SPE performance of the carbonized composites were explained in terms of their porous structure, which depended on the route followed in the carbonization process. It was suggested that this process was predominantly influenced by the properties of the nanofillers employed, e.g., their high thermal conductivity, tendency to agglomerate and interactions with resin components.
\end{abstract}

Received 25th October 2016
Accepted 2nd January 2017

DOI: $10.1039 / \mathrm{c} 6 \mathrm{ra} 25822 \mathrm{k}$

www.rsc.org/advances nanomaterials, some attempts have also been made to employ them in SPE, which has been discussed in a few reviews. ${ }^{5,6}$ In accordance with the reports just mentioned, the most frequently used carbon nanomaterials include single and multiwall nanotubes, graphene and graphene oxide. The major advantages of these adsorbents, in comparison with the most commonly used graphitized adsorbents of the GCB (graphitized carbon black) and PGC (porous graphitic carbon) types, ${ }^{3}$ are a large specific surface area to volume ratio, higher affinity for the analyzed substances and a wide spectrum of chemical modifications. However, from the viewpoint of the fundamental requirements related to adsorbents in $\mathrm{SPE},{ }^{7}$ nanocarbons exhibit certain drawbacks which make their direct use in "classic" syringe- or cartridge-type SPE columns difficult. Mention may also be made of their particle size, where one dimension (diameter/thickness) is on the nm scale, whereas the remaining dimensions are as large as several dozen $\mu \mathrm{m}$. The significant polydispersity of these dimensions is also worthy of note. ${ }^{8}$ A bed formed from such materials may exhibit low permeability or even be entirely impermeable to the samples under analysis. In addition, small adsorbent particles may pass through the bottom filter that supports the bed and contaminate the extracts. Bed settling connected with dislocation of the smallest particles of the material most commonly results in channeling and considerable variability in recovery. Another disadvantage of carbon nanomaterials is the tendency of their
Ukraine

${ }^{b}$ Faculty of Chemistry, Warsaw University of Technology, Noakowskiego 3, 00-664 Warsaw, Poland. E-mail: wtomaszewski@ch.pw.edu.pl

${ }^{c}$ Faculty of Chemistry, Maria Curie-Skłodowska University, Maria Curie Sklodowska Sq 3, 20-031 Lublin, Poland

$\dagger$ Electronic supplementary information (ESI) available: Table SI 1. The results of the analysis of variance ( $F$-Snedecor's test) for the adsorption and desorption rates. See DOI: $10.1039 / \mathrm{c} 6 \mathrm{ra} 25822 \mathrm{k}$ 
particles to aggregate, which may restrict their sorptive capacity. ${ }^{8}$ A recommended solution of the abovementioned problems has proved to be the preparation of graphene-based beds or beds based on nanotubes immobilized on a solid support or introduced into a sample matrix. In the former case use was made, for instance, of stir-bar sorptive extraction, ${ }^{9}$ SPME, ${ }^{\mathbf{1 0}}$ membranes, ${ }^{\mathbf{1 1}}$ polymeric composites ${ }^{\mathbf{1 2}}$ or inorganic composites. ${ }^{13}$ On the other hand, the dispersion of adsorbents into the sample matrix was accomplished by a number of methods, i.e., by direct addition of carbon adsorbents to solid samples, followed by extraction with solvents, in the method referred to as matrix solid-phase extraction (MSPD), ${ }^{\mathbf{1 4}}$ by addition to liquid samples with subsequent mechanical shaking, which is known as dispersive SPE (dSPE), ${ }^{\mathbf{1 5}}$ and in an analogous way using magnetic adsorbent particles, which is known as magnetic SPE (MSPE), ${ }^{16}$ in which the stirring, separation and extraction of the bed were made easier by the magnetic properties of the adsorbent particles.

Despite the rather unavoidable drawbacks of conventional cylindrical beds formed from nanocarbons, studies can be found in which such a solution has continued to be used. By way of examples, a glass column packed with $20 \mathrm{mg}$ graphene was employed for the extraction of chlorophenols from aqueous samples, ${ }^{17}$ and a column containing $30 \mathrm{mg}$ carbon nanotubes for the determination of pesticides in virgin olive oil. ${ }^{18}$ Attention should be called to the fact that the classical SPE column provides one of the simplest and at the same time most easily repeatable procedures for the extraction of liquid samples: sample loading, bed drying and desorption are simple manual operations. Thus, in this work we have decided to employ this classical SPE format with the use of beds containing carbon nanotubes or exfoliated graphite, yet in an immobilized form in a polymer matrix. The composites that were prepared, which contained $2.5 \%$ nanofiller, were based on resorcinol-formaldehyde resin. The initial carbon-polymer composites were also subjected to further carbonization to obtain, as a result, two carbon/carbon nanotubes and carbon/exfoliated graphite composites. The adsorbents obtained were used in the extraction of explosives that belonged to a variety of groups, i.e., nitramines, nitric acid esters, and nitroaromatics, from aqueous samples. One of the reasons underlying the decision to launch studies of this kind is the fact that currently no reference can be found to the employment of nanocarbons in the SPE of explosives. Furthermore, the search for selective adsorbents for trapping explosives continues to be a significant analytical issue as, for example, imprinted polymers have still not seen more uses than the determination of certain nitroaromatics, e.g., trinitrotoluene. ${ }^{19}$ It is also a matter of common knowledge that the contamination of the natural environment with carcinogenic explosives in the areas affected by numerous military conflicts is currently growing at an immense rate. ${ }^{\mathbf{2 0}}$

\section{Experimental}

\subsection{Materials}

The following materials were used: resorcinol (Farm, China), formaldehyde solution (37 wt\% aqueous solution) and anhydrous sodium carbonate (Sigma-Aldrich), distilled water, multiwalled carbon nanotubes (CNT) (Development Department of Chuiko Institute of Surface Chemistry of NAS of Ukraine) and exfoliated graphite (EG) (Termografenit-E, Ukraine).

\subsection{Preparation of nanocomposites}

The general synthesis scheme of the resin (RF) composites consisted of the following steps: the estimated amount of resorcinol was added to a solution of sodium carbonate $(0.02 \mathrm{M})$ under stirring and, after the complete dissolution of all components, formaldehyde was added at room temperature. Then, either CNT or EG was added using mechanical stirring, with subsequent ultrasonic treatment in order to obtain a homogeneous suspension. This mixture was hermetically sealed, placed in a thermostatic oven, and treated at $85{ }^{\circ} \mathrm{C}$ for $20 \mathrm{~h}$. A polymerization reaction took place with the formation of a dark brown solid polymer composite, which was then dried at $90{ }^{\circ} \mathrm{C}$ for $10 \mathrm{~h}$, milled and sieved in order to obtain a $0.25-0.50 \mathrm{~mm}$ fraction. Two initial composites were obtained, i.e., RFR-43 (with CNT) and RFR-44 (EG). Then, the composites were placed in quartz tubes and set in a tubular furnace in a vertical position. The polymers were carbonized under an argon atmosphere from room temperature to $800{ }^{\circ} \mathrm{C}$ at a heating rate of $5{ }^{\circ} \mathrm{C} \mathrm{min}^{-1}$ and were kept at the maximum temperature for $2 \mathrm{~h}$. The inflow of argon and outflow of the volatile reaction products took place through the tube at the top of the furnace. This structure ensured that the atmosphere in the reaction zone contained not only argon but also the volatile products of pyrolysis. Two carbonized composites were obtained, i.e., RFC-43 (CNT) and RFC-44 (EG). The initial compositions of the reaction mixtures are shown in Table 1.

\subsection{Characterization methods}

The surface topography of the prepared samples was studied using Quanta 3D FEG (FEI, USA) and JEOL JSM 6700F (USA) high-resolution scanning electron microscopes.

Raman spectra were recorded using an inVia Reflex Raman microscope (DMLM, Leica Research grade, Renishaw, UK). Excitation was achieved using a $514 \mathrm{~nm}$ laser.

Thermal analysis, including thermogravimetry (TG), differential thermogravimetry (DTG) and differential thermal analysis (DTA), was carried out using a Derivatograph C (MOM, Hungary). A ceramic crucible was used with a sample with a weight of $25-28 \mathrm{mg}$.

To analyze the textural characteristics, low-temperature (77.4 K) nitrogen adsorption-desorption isotherms were recorded using a Micromeritics ASAP 2405N adsorption analyzer.

The specific surface area $\left(S_{\mathrm{BET}}\right)$ was calculated according to the standard BET method. ${ }^{21}$ The total pore volume $V_{\mathrm{p}}$ was determined from the adsorption of nitrogen at $p / p_{0}=0.98-0.99$ ( $p$ and $p_{0}$ denote the equilibrium and saturation pressures of nitrogen at $77.4 \mathrm{~K}$, respectively). Non-local density functional theory (NLDFT) with models of slit/cylindrical pores in carbons was used to calculate the differential pore size distribution (PSD) $(\mathrm{d} V / \mathrm{d} R) .{ }^{22}$ Furthermore, the surface areas related to micropores were calculated by the $t$-plot method. 
Table 1 Summary of the preparation of RF composites ${ }^{a}$

\begin{tabular}{lllll}
\hline & & \multicolumn{2}{l}{ Components ratio } & \\
\cline { 3 - 4 } Sample & Filler content $(\mathrm{wt} \%)$ & $\mathrm{R} / \mathrm{W}\left(\mathrm{g} \mathrm{g}^{-1}\right)$ & $\mathrm{R} / \mathrm{F}\left(\mathrm{mol} \mathrm{mol}^{-1}\right)$ & $\mathrm{R} / \mathrm{Na}\left(\mathrm{mol} \mathrm{mol}^{-1}\right)$ \\
\hline RFR-43 & CNT, 2.5 & $1 / 4.44$ & $1 / 2$ & $130 / 1$ \\
RFR-44 & EG, 2.5 & $1 / 4.44$ & $1 / 2$ & $130 / 1$
\end{tabular}

${ }^{a} \mathrm{R} / \mathrm{W}, \mathrm{R} / \mathrm{F}$ and $\mathrm{R} / \mathrm{Na}$ are the weight ratio of resorcinol to water and the mole ratios of resorcinol to formaldehyde and the $\mathrm{Na}_{2} \mathrm{CO}_{3}$ catalyst, respectively. The filler content is the content by weight in the composite $v s$. resorcinol.

\subsection{Solid-phase extraction}

SPE columns containing $100 \mathrm{mg}$ of an adsorbent were prepared using $3 \mathrm{~mL}$ polyethylene tubes with Teflon frits (Baker). The columns were rinsed with $5 \mathrm{~mL}$ acetonitrile (ACN) and conditioned with $5 \mathrm{~mL}$ water. Then, $10 \mathrm{~mL}$ aqueous solutions of samples (containing 5 vol\% ACN to ensure solubility of the explosives) were applied and the effluents were collected. Then, $5 \mathrm{~mL}$ ACN extracts collected in $10 \mathrm{~mL}$ flasks were made up with water. The initial concentration of the explosives in the samples was $0.005 \mathrm{mg} \mathrm{mL} \mathrm{m}^{-1}$. The following three groups of explosives were used: nitrate esters, i.e., diethyleneglycol dinitrate (DNTG), trinitroglycerin (NG), and pentaerythritol tetranitrate (PETN); nitroaromatics, i.e., 2,4-dinitrotoluene (DNT) and 2,4,6-trinitrotoluene (TNT); and nitramines, i.e., RDX (hexogen), HMX (octogen), CL-20 (2,4,6,8,10,12-hexanitro-2,4,6,8,10,12-hexaazaisowurtzitane) and TEX (4,10-dinitro-2,6,8,12-tetraoxa-4,10diaza-isowurtzitane). NG was obtained from SPP Pionki (Poland). DNTG and nitramines were synthesized at the Faculty of Chemistry, Warsaw University of Technology. PETN and nitroaromatics were obtained from different sources. The purity of the explosives was determined by chromatographic and thermal methods. Quantification by HPLC was carried out as previously reported. ${ }^{23}$ Using the concentrations of the explosives determined in the effluent $C_{\text {eff }}$ and in the extract $C_{\text {ext }}$, as well as the initial concentration in the samples $C_{\text {ref }}=0.005 \mathrm{mg}$ $\mathrm{mL}^{-1}$, the following parameters that described the SPE results were calculated: the adsorption rate $R_{\mathrm{ads}}$, desorption rate $R_{\mathrm{des}}$, and recovery rate $R_{\text {rec }}$. These parameters, expressed as percentage values, were calculated according to the following expressions:

$$
\begin{gathered}
R_{\mathrm{ads}}=\left(\frac{C_{\mathrm{ref}}-C_{\mathrm{eff}}}{C_{\mathrm{ref}}}\right) \times 100 \\
R_{\mathrm{des}}=\left(\frac{C_{\mathrm{ext}}}{C_{\mathrm{ref}}-C_{\mathrm{eff}}}\right) \times 100 \\
R_{\mathrm{rec}}=\frac{R_{\mathrm{ads}} \times R_{\mathrm{des}}}{100}=\left(\frac{C_{\mathrm{ext}}}{C_{\mathrm{ref}}}\right) \times 100
\end{gathered}
$$

\section{Results and discussion}

\subsection{Characteristics of the composites}

3.1.1 Scanning electron microscopy (SEM) imaging. Fig. 1 shows SEM images of the prepared composites. The morphological characteristics of both the polymer and the carbon samples were strongly influenced by the presence of the nanofillers. Images of the surfaces of RFR-43 and RFR-44 can be seen in Fig. 1a and c, respectively. Fig. 1a shows the presence of numerous fragments, i.e., segments of isolated CNTs, immobilized in the polymeric matrix. Although the surface distribution of CNTs seems to be quite homogeneous, some bundles of nanotubes can be observed in this picture. The relatively homogeneous distribution of CNTs can be attributed to their favorable interaction with the components of resorcinol-formaldehyde resin. ${ }^{24}$ On the other hand, for the RFR-44 sample a heterogeneous arrangement of EG agglomerates on the fractured surface is a more characteristic picture. The tendency of
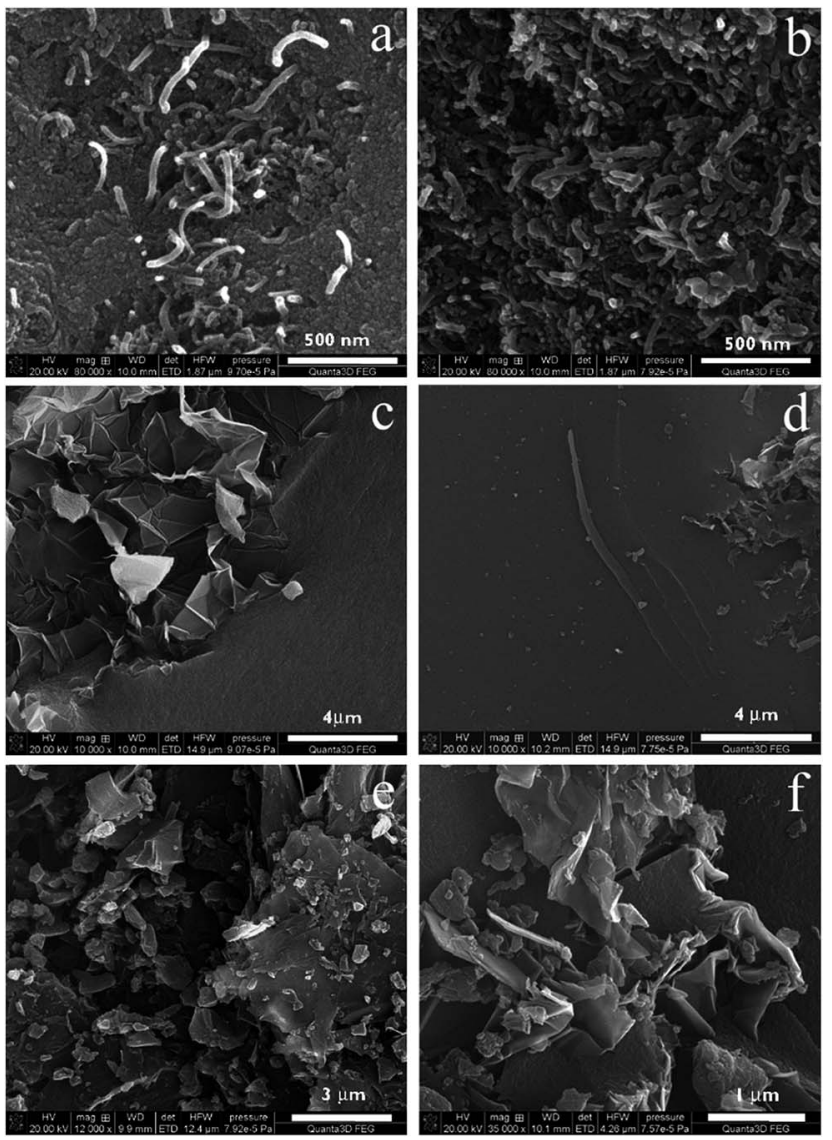

Fig. 1 SEM images: RFR-43 (a) and RFC-43 (b), magnification $\times 80$ 000; RFR-44 (c) and RFC-44 (d-f); magnifications: (c and d) $\times 10000$, (e) $\times 12000$, (f) $\times 35000$. 
graphite nanosheets to stack into aggregates in polymeric composite materials was observed earlier by $\mathrm{Wu}$ et $a .^{25}$ While discussing SEM images, it is worthwhile to draw attention to the surface of the resin substrate in the composites. For RFR-43 the surface is rough and contains a number of voids or defects, whereas for RFR-44 it is smooth and flat. The probable reason is a multidirectional distribution of CNTs in the polymer matrix ${ }^{26}$ and therefore on the surface of the composite. Typical SEM images of the resulting materials obtained after carbonization of the polymeric composites are shown in Fig. 1b (RFC-43) and Fig. 1d-f (RFC-44). The morphologies of RFR-44 and RFC-44 are alike in some respects, because for both composites smooth fragments on the matrix surface, i.e., the initial resin or carbonized surface, represent the most common picture. The difference is the distribution of the EG filler; in fact, for the RFC44 sample EG aggregates cannot be observed, as is the case for RFR-44. Only thin graphite sheets or their bent fragments can be recognized, which are most often covered with small fragments or splinters of carbonized resin (Fig. 1e and f). The fragmentation of EG agglomerates results from a number of reasons such as matrix shrinkage and stress accumulation that occurred at the carbonization stage, as well as weak interfacial bonding at the graphite-polymer interfaces. ${ }^{27}$ Furthermore, the surface of RFR-43 changed much more during carbonization. The established framework of the carbonizate mainly contains "brushes" of randomly assembled nanotubes, and no structures corresponding to carbonized resin fragments can be observed. It is noteworthy that the CNTs in the RFC-43 composite seem to be thicker and rougher than in the initial material. This may be caused by the layer of pyrolytic or graphitic carbon deposited on the nanotubes, ${ }^{28}$ which originated from the decomposition of the bulk resin.

3.1.2 Raman spectroscopy. The morphology of carbonaceous materials substantially depends on the presence of structural elements with $\mathrm{sp}^{3}$ (disordered carbon) and $\mathrm{sp}^{2}$ (graphite-like carbon) hybridization. The relative contents of these structures can be determined from Raman spectra ${ }^{29,30}$ using the intensity ratio of two bands, which are denoted by the $\mathrm{D}$ and $\mathrm{G}$ symbols. These bands correspond to the vibrations of disordered and ordered carbon structures. The Raman spectra of the composites and nanofillers are presented in Fig. 2. The band observed for both fillers at $2680-2720 \mathrm{~cm}^{-1}$ is an overtone of the D-band and is not taken into consideration. Deconvolution of the D and G-bands shows an additional two bands (Fig. ESI 1. ESI $\dagger$ ). The $\mathrm{G}_{1}$ band at $1525 \mathrm{~cm}^{-1}$ relates to carbon structures in the amorphous state, ${ }^{31}$ whereas the $\mathrm{D}_{1}$ band in the region of low frequencies at about $1100-1200 \mathrm{~cm}^{-1}$ has no unambiguous interpretation according to the literature to date. Therefore, the ratio of disordered to graphite-like carbon in the samples was calculated using the integral intensities of the $\mathrm{D}_{2}$ and $\mathrm{G}_{2}$ bands $\left(A_{\mathrm{D}_{2}} / A_{\mathrm{G}_{2}}\right)$. The results of analysis of the Raman spectra, including the degree of crystallinity of the carbon samples, are shown in Table 2.

These results indicate that the surface of the RFC- 43 sample, despite the presence of a filler with a lower degree of crystallinity, has a more ordered structure in comparison to RFC-44. These conclusions represent a good complement to the

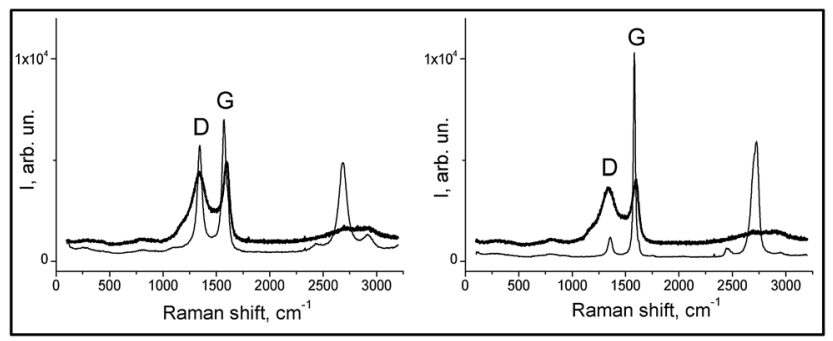

Fig. 2 Raman spectra of the composites (thick lines): RFC-43 lefthand graph, RFC-44 right-hand graph, and fillers (thin lines): CNT on the left-hand side and EG on the right-hand side.

Table 2 Frequencies of the Raman shift at the respective maxima of the band components and the values of the $A_{D_{2}} / A_{G_{2}}$ ratio

\begin{tabular}{llllll}
\hline Sample & $\mathrm{D}_{1}\left(\mathrm{~cm}^{-1}\right)$ & $\mathrm{D}_{2}\left(\mathrm{~cm}^{-1}\right)$ & $\mathrm{G}_{1}\left(\mathrm{~cm}^{-1}\right)$ & $\mathrm{G}_{2}\left(\mathrm{~cm}^{-1}\right)$ & $A_{\mathrm{D}_{2}} / A_{\mathrm{G}_{2}}$ \\
\hline $\mathrm{CNT}$ & 1183 & 1344 & - & 1574 & 0.82 \\
EG & - & 1356 & - & 1582 & 0.22 \\
RFC-43 & 1190 & 1340 & 1520 & 1595 & 2.66 \\
RFC-44 & 1182 & 1340 & 1524 & 1595 & 2.93
\end{tabular}

conclusions that can be drawn from the SEM observation: in fact, they even suggest a coincidence with the latter conclusions. At this point, it may be advisable to recall the conclusions from SEM observations, which indicate that the RFC-43 composite is formed from rather regularly spaced, even though randomly arranged, CNTs. In the case of RFC-44, a manifest disintegration of EG agglomerates has taken place, and its surface consists largely of planes formed from amorphous resinous carbonizate. For RFC-43, parts of the CNTs seem, on the basis of the changed appearance of their surface, to be covered with amorphous carbon. The higher degree of order of the RFC-43 surface may also result from the fact that CNT inclusions, on account of their exceptionally high thermal conductivity, may bring about, as in the case of nanodiamonds, ${ }^{32}$ localized graphitization.

3.1.3 Porous structure. The characteristics of the porous structure (Table 3) were determined from the low-temperature nitrogen adsorption/desorption isotherms illustrated in Fig. 3a and c. According to IUPAC recommendations, ${ }^{33}$ these isotherms belong to type IV with hysteresis loops of H2 type. The sharp rise in adsorption in the low-pressure range is attributed to micropores, whereas the hysteresis between the adsorption and desorption curves in the pressure range of 0.41.0 indicates capillary condensation in mesopores. The PSDs of the polymeric composites (Fig. 3b) are quite similar. The main contributions to their porosity are due to both micro- and mesopores $\left(V_{\text {micro }} / V_{\mathrm{p}}\right.$, Table 3$)$. Carbonization significantly changed the porosity of samples, which are now mainly microporous. This resulted from matrix shrinkage that occurred at the carbonization stage. The contribution of micropores to the total porosity of RFC-43 and RFC-44 increased by nearly half $\left(V_{\text {micro }} / V_{\mathrm{p}}\right)$. The RFC-44 sample is more microporous than RFC-43. The difference arises mainly from the 
Table 3 Textural characteristics of the composites ${ }^{a}$

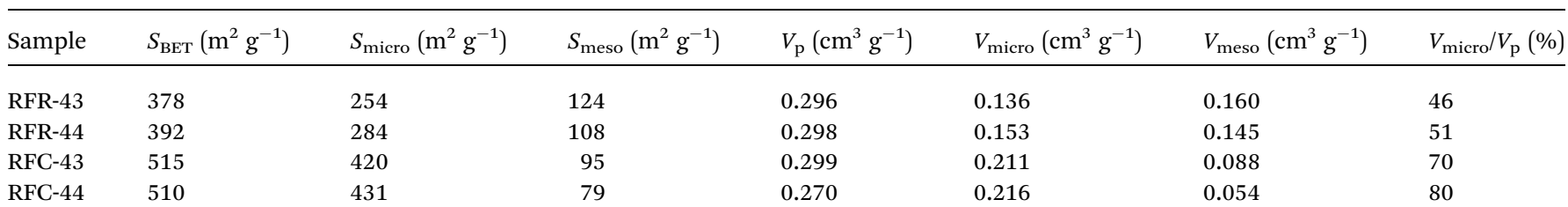

${ }^{a} S_{\mathrm{BET}}$ is the specific surface area; $S_{\text {micro }}$ is the specific surface area of micropores determined by the $t$-plot method; $S_{\text {meso }}$ is the specific surface area

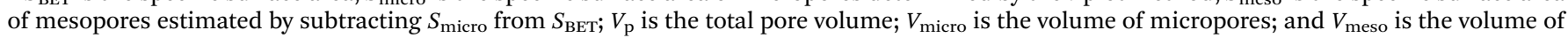
mesopores calculated by subtracting $V_{\text {micro }}$ from $V_{\mathrm{p}}$.

presence of a narrow fraction of micropores with a radius of $0.8 \mathrm{~nm}$. It can be assumed that this fraction of pores represents the residue of the pores that are apparent in the polymeric samples (Fig. 3b). This proves that, owing to the presence of specific nanofillers (CNT or EG), the routes followed in the carbonization of the polymeric matrix are different.

3.1.4 Thermogravimetric analysis. The TG curves (Fig. 4) do not differ extremely and have a monotonic character of weight loss above $400{ }^{\circ} \mathrm{C}$. Therefore, the extremes in the DTG curves (Fig. 4) relate to small changes in the weight of the samples. The first peak in weight loss at $80-85{ }^{\circ} \mathrm{C}$ is due to the desorption of physisorbed water. The second stage begins at $T$ $>350{ }^{\circ} \mathrm{C}$. At this stage, intensive oxidation of the carbon phase in the range of $500-800{ }^{\circ} \mathrm{C}\left(T_{\max }=645{ }^{\circ} \mathrm{C}\right)$ is observed, with a weight loss of the sample of about $27-32 \%$. During the third stage, an increase in temperature to $1170{ }^{\circ} \mathrm{C}$ did not lead to complete combustion of the material, and the residual weight was $5-10 \%$. From the trends of the TG and DTG curves for both adsorbents, it may be concluded that the weight losses over the range up to $900{ }^{\circ} \mathrm{C}$ are the result of combustion of the carbonaceous matter formed by pyrolysis of the resin. Above $900{ }^{\circ} \mathrm{C}$, however, the courses of the DTG and DTA (Fig. 4)

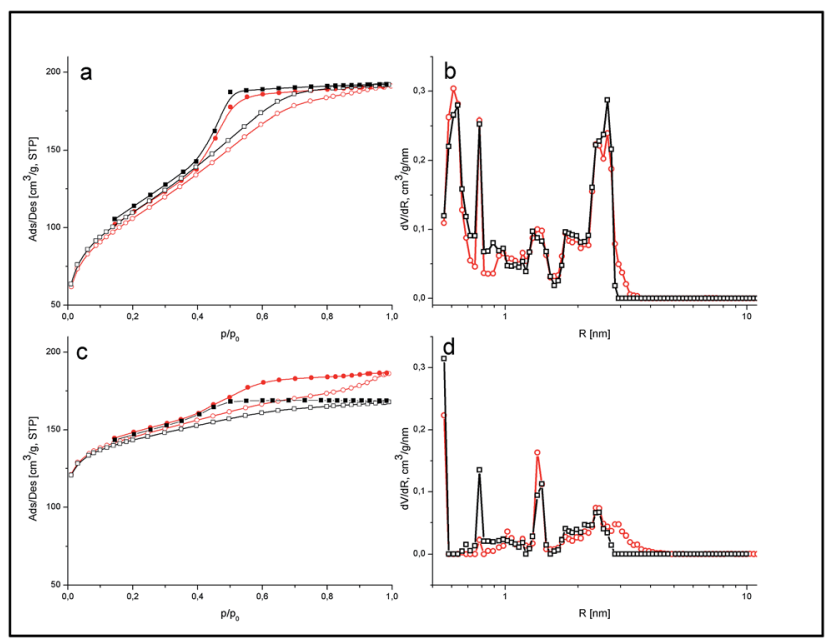

Fig. 3 Nitrogen adsorption/desorption isotherms ( $a$ and $c$ ) and pore size distributions ( $b$ and $d$ ) of the polymeric ( $a$ and $b$ ) and carbonized ( $c$ and d) composites. For both isotherms and PSDs, circles represent RFR-43 and RFC-43, whereas squares represent RFR-44 and RFC-44. For isotherms open symbols represent adsorption, whereas full symbols represent desorption. curves for both adsorbents are different. For the graphitecontaining RFC-44 sample, the combustion process follows a monotonic pattern. On the DTG curve for this adsorbent a single peak is visible, with a minimum at $1100{ }^{\circ} \mathrm{C}$ and a tiny exothermic peak at the same temperature. In the case of the nanotube-containing RFC-43 sample, in contrast, a two-stage combustion process above $900{ }^{\circ} \mathrm{C}$ may be justifiably suggested. Two peaks with minima at $1000{ }^{\circ} \mathrm{C}$ and $1100{ }^{\circ} \mathrm{C}$ can be distinguished on the DTG curve. This is reflected in the trend of the DTA curve for this adsorbent, in which in the range of 1000 to $1200{ }^{\circ} \mathrm{C}$ two exothermic peaks can be noticed, namely, one of a lesser size with a maximum at $1050{ }^{\circ} \mathrm{C}$ and another of high intensity at $1150{ }^{\circ} \mathrm{C}$. The differences observed between the trends of the DTG and DTA curves under consideration for the RFC-43 and RFC-44 adsorbents are most probably due to the structure of both carbonaceous materials used as fillers. The crystal structure of graphite, which is composed of graphene sheets arranged in a flat pattern one upon another, accounts for the fact that the process of combustion of this material would proceed in a monotonic manner. On the other hand, a more complex CNT structure made of graphene sheets "rolled up" into a tubular form would be responsible for the fact that during combustion oxygen can also penetrate into the internal structure of the nanotube, which could result in the process being more complex and proceeding more exothermically.

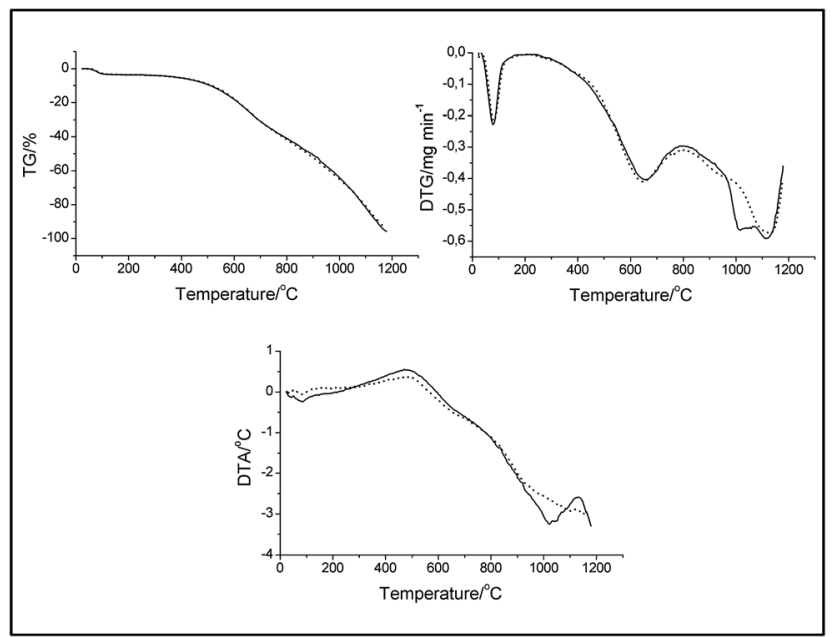

Fig. 4 TG, DTG and DTA curves for RFC-43 (solid lines) and RFC-44 (dashed lines) composites. 


\subsection{SPE results}

To facilitate the comparison of the average $R_{\text {ads }}, R_{\text {des }}$ and $R_{\text {rec }}$ values for individual substances on two analogous adsorbents, i.e., the two RFR composites and two RFC carbonizates, a statistical test was applied, i.e., the analysis of variance or the $F$-Snedecor test for the statistical comparison of intra- and intergroup variation. ${ }^{34}$ For a level of significance of $p=0.05$ and for a number of degrees of freedom of $f=1=2-1$ (two adsorbents) and $f=4=6-2$ (6 measurements, i.e., three for each adsorbent), the value of the $F$ statistic was determined and was then compared with the critical value of $F_{0.05,1,4}$, which was equal to 7.71 (Table ESI 1, ESI $\dagger$ ). In the case when $F<F_{0.05,1,4}$, it was assumed that the observed rates (adsorption and desorption) did not differ from one another; in the contrary case, it was assumed that there existed statistically significant differences between these results.

SPE experiments were also performed with two additional adsorbents without nanofillers, namely, a resin and its carbonization product, which were obtained under the same conditions as the RFR and RFC composites. It was found that the retention of the studied explosives on such adsorbents was negligible, which means that the adsorption rates observed were lower than $5 \%$. Taking into consideration the uncertainty in the SPE results, which reached $c a$. 4-6\%, it was assumed that the polymeric or carbonaceous matrix had no significant impact on the SPE results.

3.2.1 Resin composites RFR-43 and RFR-44. The SPE results obtained for the RFR-43 and RFR-44 composites are collated in Fig. 5. The adsorption rates $\left(R_{\mathrm{ads}}\right)$ shown in the upper graph attained values in the range of $50-100 \%$. The lowest values were obtained for nitroglycerin and the highest for the two nitroaromatics. The high $R_{\text {ads }}$ values for TNT and DNT resulted from strong $\pi-\pi$-type interactions of these molecules with the aromatic groups of the resins or graphene planes of the fillers. The reason for the low $R_{\text {ads }}$ values for $\mathrm{NG}$ on both adsorbents may be seen in the formation by this molecule in aqueous solutions of associated forms, e.g., dimers, which give rise to weaker adsorption, as was suggested recently. ${ }^{23}$ Taking into consideration the $F$ statistics, it may be assumed that the $R_{\text {ads }}$ values for nitramines and nitroaromatic compounds on RFR-43 and RFR-44 do not differ from one another. As regards the nitrate esters (NG, DNTG, and PETN), the $R_{\text {ads }}$ values differ from one another, and are lower by greater than $10 \%$ for the nanotube-containing RFR-43 sample. This adsorbent features a somewhat smaller specific surface area (cf. Table 3). This, however, had no adsorption-suppressing effect with the remaining explosives. Accordingly, the effect of this factor can be disregarded.

It follows from the SEM images (Fig. 1a) that either the nanotube fragments or one or both tube ends are covered with a polymer layer. For the EG-containing composite, considerable fragments of the filler aggregate remain outside the polymer matrix. The surface oxygen functionalities in the case of both CNTs and EG are known to be primarily located (disregarding the presence of surface defects) at the edges of the graphene planes. In nanotubes, they are located at their ends, whereas in

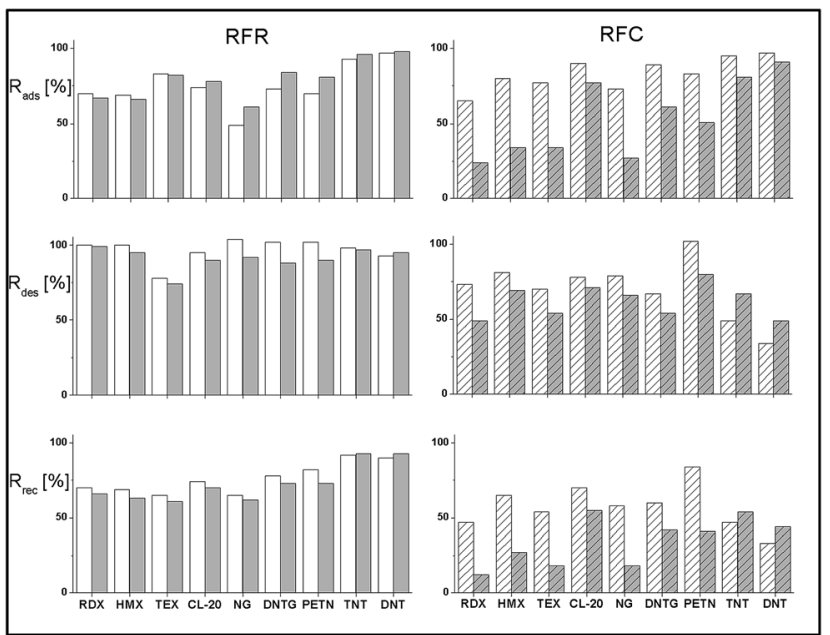

Fig. 5 SPE results: adsorption rate (upper graphs), desorption rate (middle graphs) and recovery rate (lower graphs). The left-hand graphs represent resins, whereas the right-hand graphs represent carbonized samples. In each graph white bars indicate the results for CNT composites, grey bars the results for EG composites. In the individual graphs the pairs of bars successively represent RDX, HMX, TEX, CL-20, NG, DNTG, PETN, TNT, and DNT.

graphite, they are located at the edges of graphene surfaces. Taking into consideration the distribution of carbon fillers in the polymer matrix, it can be assumed that the number of surface oxygen groups available on the surface of the RFR-44 composite is significantly greater than that on RFR-43. This conclusion is in good agreement with the results of XPS measurements, which enabled the surface concentration of the major oxygen functionalities to be quantified (Table ESI 2, ESI $\dagger$ ). The results demonstrate that the surface concentration of polar carbonyl groups was higher on the RFC-44 composite in comparison to the RFC-43 composite. Moreover, it was demonstrated in earlier studies ${ }^{\mathbf{3 5}}$ that nitrate esters are weakly adsorbed on graphitized carbons, whereas they effectively become concentrated on oxidized carbons. Considering these two facts together, the weaker adsorption of nitrate esters on the RFR-43 composites in comparison with the RFR-44 composites appears understandable.

The desorption rates presented in the middle graph attained, with the exception of TEX, high values in the range of 90 to $100 \%$. The low $R_{\text {des }}$ value for TEX in contrast to the other explosives was most probably due to the small size of this molecule. $^{36}$ The $D_{\min }$ value, which is equal to $0.49 \mathrm{~nm}$, is comparable to the size of the smallest molecules of recognized explosives. The $D_{\max }$ value, however, which barely equals $0.78 \mathrm{~nm}$, is already the lowest among the remainder of these substances. Therefore, TEX molecules may become adsorbed in small pores into which the penetration of other explosives is rendered more difficult. A smaller pore size results in stronger interactions of TEX particles with the pore walls, which results in a decline in their desorption by acetonitrile.

On the basis of the $F$ statistics, it may be assumed that the $R_{\text {des }}$ values for nitramines and nitroaromatics on the RFR-43 and RFR-44 adsorbents do not differ from one another. As 
regards the aliphatic nitrates (NG, DNTG, and PETN), the $R_{\text {des }}$ values differ from one another and are greater by 12 to $14 \%$ for the RFR-43 composite. The more effective desorption of these esters correlates with their weaker adsorption, as discussed above.

The final parameter that describes the efficiency of the SPE method is the recovery rate $R_{\text {rec}}$, which depends on both the adsorption and the desorption rate (see eqn (3)). It determines the effectiveness of the isolation of an analyte from a sample and thus the selectivity of the SPE method employed. The recovery rates on RFR-43 and RFR-44 (Fig. 5, lower left-hand graph) show that the highest values (over 90\%) were for TNT and DNT. The $R_{\text {rec }}$ values for the majority of esters and nitramines fell within the range of 60 to $80 \%$. For both esters and nitramines, the lower $R_{\text {rec }}$ values stemmed from their weaker adsorption in comparison with the aromatic explosives. Such recovery rates in excess of $50 \%$ are an excellent starting point for further optimization of the method. ${ }^{37}$

3.2.2 Carbonized composites RFC-43 and RFC-44. The SPE results on the carbonized materials are summarized in Fig. 5. As the porous structures (see the nitrogen adsorption results) of the polymeric composites used to make the RFC- 43 and RFC- 44 samples were very similar, in combination with the fact that similar SPE results were obtained on RFR-43 and RFR-44, there were some expectations that both carbonizates would likewise exhibit similar properties as regards their adsorption/ desorption characteristics for explosives. These characteristics, however, proved to be different. The considerable differences in $R_{\text {ads }}$ and $R_{\text {des }}$ visible in Fig. 5 (also confirmed statistically) indicate that the fillers used, i.e., nanotubes and exfoliated graphite, were the reason for the diverse forms of carbonization of the composites. This conclusion is in good agreement with SEM observations and the results of Raman spectroscopy studies. The adsorption rates obtained on RFC-43, which are shown in the upper graph in Fig. 5, for all of the compounds examined, apart from the nitroaromatics, fell within the range of 60 to $90 \%$. On the other hand, the even higher $R_{\text {ads }}$ values for TNT and DNT resulted from preferential $\pi-\pi$-type interactions of these aromatic molecules with graphene surfaces. The lower $R_{\text {ads }}$ values for nitroaromatics on RFC-44 resulted from the reduced accessibility of such structures on its surface in comparison with RFC-43 (Table 2). The adsorption of the other explosives on the RFC-44 adsorbent was weaker and in some cases reached as little as half or even onethird of the values attained on RFC-43. The RFC-44 composite is, to a considerable degree, a microporous adsorbent, in comparison with RFC-43. The results of a recent ${ }^{1} \mathrm{H}$ NMR study of chars that were obtained by carbonization of analogous resorcinol-formaldehyde resins ${ }^{38}$ correlate favorably with the SPE results. The authors found that the micropores in such chars were poorly available to organic co-adsorbates on account of blocking of their interior by water molecules. The abovementioned study adequately explains the remarkable difference in $R_{\text {ads }}$ found for non-aromatic explosives on RFC-44 in comparison to RFC-43, which has wider mesopores that are accessible to adsorbates. In addition, it should be borne in mind that the reduced availability of micropores had no effect on the adsorption of nitroaromatics on graphene surfaces. In discussing the results of the desorption of explosives from the carbon adsorbents under investigation, their porous structures should also be taken into consideration. In the cases of those ester and nitramine molecules that became adsorbed in the narrow micropores of RFC-44, the lower $R_{\mathrm{des}}$ values resulted from their strong adsorption and insufficient elution strength of acetonitrile for effective desorption. The better desorption of nitroaromatics from RFC-44, on the other hand, resulted from the fact that they were adsorbed on the outer graphene planes rather than in slit-like pores formed by such structures. The presence of such pores in the case of the more highly graphitized RFC-43 appears to be more justified (Table 2), which was demonstrated by the stronger adsorption of nitroaromatics on this adsorbent. The recovery rates on RFC-43 and RFC-44, which did not exceed $70 \%$, with the exception of PETN, were much worse in comparison with those on the starting polymeric composites. The conclusions that can be drawn from the individual steps on which $R_{\text {rec }}$ depends, namely, adsorption and desorption, facilitate the planning of additional experiments, which it is hoped will permit an increase in $R_{\text {rec }}$. Specifically, to increase the adsorption rate on RFC- 44 carbon the bed size may be increased, whereas at the desorption stage satisfactory results may be expected from the application of solvents of a higher elution strength, e.g., dimethylformamide, ${ }^{39}$ to carbon adsorbents. The results of such investigations, as well as the application of the adsorbents studied to real samples, e.g., surface waters, will be the subject of a separate communication.

\section{Conclusions}

Four novel composites containing nanocarbons, i.e., carbon nanotubes and exfoliated graphite immobilized in polymeric and carbon matrices, were prepared. The initial two composites were obtained using resorcinol-formaldehyde resin and the two additional composites by their subsequent carbonization. Columns packed with the composites proved to be useful for SPE experiments. The beds were stable, the particles of adsorbents did not settle, and excellent permeability for the solvents used (water and acetonitrile) was observed. It must be remembered that neither the initial resin nor the applied nanocarbons can be used separately as adsorbents for solid-phase extraction. However, the derived composites, which contained only 2.5 $\mathrm{wt} \%$ of the immobilized filler, proved to be a promising material for the solid-phase extraction of aliphatic, cyclic and aromatic explosive compounds from an aqueous matrix. Both the polymeric composites and the carbonized composite with nanotubes as a filler gave high recovery rates for explosives, which reached $90 \%$. Although similar SPE results were obtained on the polymeric composites, the recoveries on the carbonized samples were quite different. This shows that the course of the carbonization process was strongly dependent on the presence of nanofillers. The differences in the adsorption and desorption rates for explosives were discussed on the basis of the surface properties (graphitization rate) and porous structures (microand mesoporosity) of the composites and the properties of the explosive molecules themselves. As an example, the polymeric 
composites are mesoporous materials, whereas the carbonized composites, to a large extent, are microporous. However, it should be emphasized that in the carbonized sample containing nanotubes mesoporosity is still demonstrated. The reasons for this are probably the homogeneous dispersion of nanotubes, their strong interactions with the resin matrix, and the stabilization of the porous structure. Therefore, the mesoporosity of the composite was partially preserved during carbonization. In addition, the carbonized sample containing exfoliated graphite is primarily microporous, and the adsorption of aliphatic explosives (nitrate esters and nitramines) in small pores is strongly hindered by water clusters.

\section{References}

1 B. Buszewski and M. Szultka, Crit. Rev. Anal. Chem., 2012, 42, 198-213.

2 G. A. Junk, J. J. Richard, M. D. Grieser, D. Witiak, J. L. Witiak, M. D. Arguello, R. Vick, H. J. Svec, J. S. Fritz and G. V. Calder, J. Chromatogr. A, 1974, 99, 745-762.

3 M. C. Hennion, J. Chromatogr. A, 2000, 885, 73-95.

4 E. Matisová and S. Skrabáková, J. Chromatogr. A, 1995, 707, 145-179.

5 K. Pyrzyńska, Sep. Purif. Rev., 2008, 37, 372-389.

6 N. Ye and P. Shi, Sep. Purif. Rev., 2015, 44, 183-198.

7 M. Henry, SPE technology - principles, and practical consequence, in Solid-phase extraction, principles, techniques, and applications, ed. N. J. K. Simpson, Marcel Dekker, New York, 2000, pp. 149-172.

8 Handbook of Carbon Nano Materials, Graphene-Fundamental Properties, ed. F. D'Souza and K. M. Kadish, World Scientific, Singapore, 2014, vol. 5, p. 159.

9 Z. Ayazi and P. Rafighi, Anal. Methods, 2015, 7, 3200-3210.

10 Q. H. Wu, C. Feng, G. Y. Zhao, C. Wang and Z. Wang, J. Sep. Sci., 2012, 35, 193-199.

11 Z. Wang, Q. Han, J. Xia, L. Xia, M. Ding and J. Tang, J. Sep. Sci., 2013, 36, 1834-1842.

12 M. R. Nabida, R. Sedghia, A. Bagheria, M. Behbahania, M. Taghizadeha, H. A. Oskooieb and M. M. Heravib, J. Hazard. Mater., 2012, 203-204, 93-100.

13 J. L. Zhang, R. M. Cheng, S. S. Tong, X. W. Gu, X. J. Quan, Y. L. Liu, Q. Jia and J. B. Jia, Talanta, 2011, 86, 114-120.

14 Q. Liu, J. Shi, J. Sun, T. Wang, L. Zeng, N. Zhu and G. Jiang, Anal. Chim. Acta, 2011, 708, 61-68.

15 R. Su, X. Xu, X. Wang, D. Li, X. Li, H. Zhang and A. Yu, J. Chromatogr. B: Anal. Technol. Biomed. Life Sci., 2011, 879, 3423-3428.

16 Y. N. Jiao, L. Ding, S. L. Fu, S. H. Zhu, H. Li and L. B. Wang, Anal. Methods, 2012, 4, 291-298.

17 Q. Liu, J. B. Shi, L. X. Zeng, T. Wang, Y. Q. Cai and G. B. Jiang, J. Chromatogr. A, 2011, 1218, 197-204.

18 S. López-Feria, S. Cárdenas and M. Valcárcel, J. Chromatogr. A, 2009, 1216, 7346-7350.
19 W. J. Cheong, S. H. Yang and F. Ali, J. Sep. Sci., 2013, 36, 609628.

$20 \mathrm{http}$ //www.thepeninsulaqatar.com/views/political-views/ 371557/syria-after-the-war-a-polluted-desert.

21 S. J. Gregg and K. S. W. Sing, Adsorption, Surface Area and Porosity, 2. Auflage, Academic Press, London, 1982, pp. 41109.

22 A. V. Neimark and P. I. Ravikovitch, Microporous Mesoporous Mater., 2001, 44/45, 697-707.

23 W. Tomaszewski and V. M. Gun'ko, J. Sep. Sci., 2015, 38, 2488-2495.

24 M. C. Gutiérrez, F. Rubio and F. del Monte, Chem. Mater., 2010, 22, 2711-2719.

25 T. L. Wu, T. S. Lo and W. S. Kuo, Polym. Compos., 2010, 31, 292-298.

26 H. Peng and X. Sun, Chem. Phys. Lett., 2009, 471, 103-105.

27 A. Yasmin, J. J. Luo and I. M. Daniel, Compos. Sci. Technol., 2006, 66, 1179-1186.

28 H. G. Chae, Y. H. Choi, M. L. Minus and S. Kumar, Compos. Sci. Technol., 2009, 69, 406-413.

29 F. Tuinstra, J. Chem. Phys., 1970, 53, 1126-1130.

30 C. S. Sharma, D. K. Upadhyay and A. Sharma, Ind. Eng. Chem. Res., 2009, 48, 8030-8036.

31 T. H. Ko, W. S. Kuo and Y. H. Chang, Polym. Compos., 2000, 21, 745-750.

32 E. Duffy, X. He, E. P. Nesterenko, D. Brabazon, A. Dey, S. Krishnamurthy, P. N. Nesterenko and B. Paull, RSC Adv., 2015, 5, 22906-22915.

33 J. Rouquerol, D. Avnir, C. W. Fairbridge, D. H. Everett, J. M. Haynes, N. Pernicone, J. D. F. Ramsay, K. S. W. Sing and K. K. Unger, Pure Appl. Chem., 1994, 66, 1739-1758.

34 P. C. Meier and R. E. Zund, Statistical Methods in Analytical Chemistry, J.Wiley \& Sons, New York, 2nd edn, 2000, pp. 69-72.

35 R. Leboda, J. Skubiszewska-Zięba, V. M. Gun'ko, W. Tomaszewski and B. J. Trznadel, J. Colloid Interface Sci., 2001, 239, 489-500.

36 W. Tomaszewski, V. M. Gun'ko, J. Skubiszewska-Zięba, B. Charmas and R. Leboda, Colloids Surf., A, 2015, 468, 7686.

37 Optimizing solid phase extraction methods, in Forensic and Clinical Applications of Solid Phase Extraction, ed. M. J. Telepchak, T. F. August and G. Chaney, Humana Press Inc., Totowa, 2004, pp. 109-128.

38 V. M. Gun'ko, V. M. Bogatyrov, V. V. Turov, R. Leboda, J. Skubiszewska-Zięba and I. V. Urubkov, Appl. Surf. Sci., 2013, 283, 683-693.

39 B. Kaur, Porous graphitic carbon, a new material for high performance liquid chromatography, Ph.D. thesis, University of Edinburgh, 1986. 